\title{
ANALIZANDO EL MODELO DE JUEZ RACIONAL. REFLEXIONES SOBRE LA TEORÍA DE LA JURISDICCIÓN EN EL NEOCONSTITUCIONALISMO
}

\author{
ANALYZING THE MODEL OF RATIONAL JUDGE. REFLECTIONS \\ UPON THE THEORY OF JURISDICTION IN THE NEW \\ CONSTITUTIONALISM.
}

\section{Cristián Villalonga Torrijo*}

\begin{abstract}
RESUMEN: El presente artículo plantea que el neoconstitucionalismo, tanto en sus bases teóricas más sofisticadas como en su desarrollo en España, Italia y Latinoamérica, se encuentra en gran medida construido en base a una ficción sobre el rol del juez. En una analogía con la conocida descripción sobre el legislador racional escrita por Carlos Santiago Nino, el trabajo revisa los principales atributos de este nuevo arquetipo judicial, cuya función sería legitimar un rol más activo de los tribunales en la esfera pública.
\end{abstract}

Palabras clave: Jueces, neoconstitucionalismo, ficciones jurídicas.

ABSTRACT: This article asserts that new-constitutional thought, both in its more sophisticated theory as in its development in Spain, Italy, and Latin America, has been built on the grounds of a fictitious model of judge. In an analogy to the well-known depiction of the rational legislator written by Carlos Santiago Nino, the article reviews the main attributes of this new model of judge, whose function is legitimating an active role of courts in the public sphere.

Key words: Judges, new constitutionalism, legal fictions.

\section{INTRODUCCIÓN}

Hace más de 30 años, Carlos Santiago Nino describía cómo la idea hipotética de un legislador racional había cumplido una función central en la dogmática jurídica. La ficción de un legislador omnisciente, coherente y único -al que casi se le asignaban las particularidades de un dios teológico-, había sido asumida de forma tácita por la jurisprudencia para lidiar con las evidentes limitaciones de las normas producidas por legisladores de carne y hueso. Por ejemplo, tal hipótesis permitía aludir a una voluntad permanente del legislador, aun cuando quienes dictaron la norma hubieren muerto. Asimismo, este supuesto facilitaba que los intérpretes afirmarán que la ley poseía una unidad de propósito, pese a que, en realidad, ella sería usualmente un acuerdo de intereses divergentes que carece de una finalidad clara. En suma, tal modelo explicaba la continuidad de una única voluntad soberana tras la

* PhD en Jurisprudence and Social Policy, University of California at Berkeley. Profesor Asistente Facultad de Derecho, Pontificia Universidad Católica de Chile. Dirección postal: Alameda 340, Santiago. Dirección electrónica: cvillalt@uc.cl. 
ley, y, al mismo tiempo, permitía su adaptación a través de interpretaciones que optimizaban su contenido ${ }^{1}$.

Este artículo plantea que el neoconstitucionalismo se encuentra en buena parte estructurado por una ficción análoga, a la que podríamos llamar el modelo del juez racional. Básicamente, en diversos autores ligados a esta corriente se asigna a la figura del juez una serie de atributos que no son empíricamente verificables, como su capacidad de interpretar la moralidad pública y de resolver los conflictos mediante una solución racional suficiente para persuadir a la ciudadanía. Este ideal de jurisdicción buscaría legitimar un rol más activo de los tribunales, en un proceso de ruptura con el sistema tradicional de separación de poderes.

La literatura reciente ha debatido sobre los diversos motivos que explican la mayor discrecionalidad de los tribunales y su menor deferencia frente al poder político. Entre otras causas, destaca la expansión del repertorio de derechos fundamentales y la creciente fragmentación política que ha impedido controlar la autoridad de los magistrados ${ }^{2}$. No obstante, aquellas causas no pueden reducirse a variables externas a la figura del juez. Adicionalmente, es posible afirmar que este cambio se encuentra vinculado a una redefinición del rol de la jurisdicción en las sociedades contemporáneas ${ }^{3}$.

Tal como sucede con la ficción descrita por Nino, ningún autor ha sostenido abiertamente la figura del juez racional de forma unitaria. Sin embargo, las diversas propiedades que gradualmente se han asignado a los tribunales a nivel teórico y discursivo, como una especie de mosaico, han redibujado su rol. Hoy podríamos afirmar que la ficción del juez racional ha permeado tanto a los mismos magistrados como a la sociedad en general, constituyendo un nuevo modelo institucional claramente reconocible.

Este artículo asume una visión crítica del neoconstitucionalismo, particularmente respecto de aquellos autores que han admitido de manera ingenua los distintos atributos que constituyen el modelo juez racional. Algunos de los cuestionamientos incluidos en el texto no son completamente nuevos, pero creo resulta conveniente analizarlos de manera conjunta. El problema fundamental descrito aquí no radica en que las propiedades asignadas a los tribunales sean irreales. Después de todo, la teoría política y jurídica está plagada de ficciones destinadas a dotar de cierta coherencia al actuar de las instituciones. Tampoco pretendo negar que esporádicamente los jueces dicten decisiones que persuadan a la ciudadanía o interpreten las preferencias morales de la opinión pública.

Me parece que se pueden oponer dos objeciones al modelo de juez racional. La primera dificultad estriba en que aquellas ficciones han influido en la comprensión que algunos jueces tienen de sus propias capacidades, tal como si fueran una realidad. Algo similar ocurre a nivel académico, pues autores como Alexy o Dworkin no aceptan abiertamente estar refriéndose a propiedades ficticias 4 . Tales afirmaciones resultan problemáticas en el plano institucional y normativo. En segundo lugar, los atributos identificados bajo este

\footnotetext{
1 Nino (2003) pp. 328-347.

2 Tate y Vallinder (1997) pp. 27-39.

3 Hilbink (2012).

4 AleXy (2005) pp. 579-580. De hecho, Dworkin plantea que su visión del juez Hércules no es solo normativa, sino también descriptiva, pues busca dar cuenta de la práctica mediante la cual efectivamente se ejerce la jurisdicción. DwORKIN (1977) pp. 123-124.
} 
modelo parecen una base teórica débil a la hora de justificar la creciente intervención de los tribunales en los asuntos públicos. Aun cuando los jueces en ocasiones puntuales resuelvan con acierto, estos últimos casos son contingentes, y no parecen ser un presupuesto general y suficiente para legitimar ex ante una visión expansiva del rol judicial desde el punto de vista teórico. Considero que ambas dificultades ponen en riesgo los requerimientos básicos de un régimen democrático y el estado de derecho.

El artículo comienza con una brevísima descripción del neoconstitucionalismo como corriente académica en el que esta ficción se encuentra inserta. A continuación, este analiza los atributos que gradualmente han conformado al modelo de juez racional a través de los principales autores que lo sustentan a nivel teórico, como Robert Alexy y Ronald Dworkin, agregando asimismo algunas notas sobre cómo estos atributos han sido desarrollados en España, Italia y Latinoamérica. Finalmente, el trabajo explica las funciones que cumple esta hipótesis, en particular, el justificar indirectamente un área de discreción en la toma de decisiones judiciales y mitigar de la responsabilidad política del juzgador.

\section{DEFINIENDO EL NEOCONSTITUCIONALISMO COMO ESPACIO DE UN NUEVO MODELO JURISDICCIONAL}

Es necesario comenzar advirtiendo sobre las dificultades de caracterizar el neoconstitucionalismo que ha originado el modelo de juez racional ${ }^{5}$. Tal como la literatura citada en este acápite describe, aquel vocablo posee diversos significados y matices, resultando altamente controversial ${ }^{6}$. Este artículo no pretende entrar detalladamente en aquel debate, prefiriendo considerar un punto de partida convencional: los intentos de descripción de este fenómeno por Susanna Pozzolo, Paolo Comanducci, Miguel Carbonell y Luis Prieto Sanchís. En este sentido, este trabajo asume que el neoconstitucionalismo consiste en una aproximación a la práctica constitucional surgida durante la segunda mitad del siglo XX, la que ha sido consolidada a lo largo del tiempo mediante una serie de formulaciones teóricas que le han dotado de densidad intelectual ${ }^{7}$.

La creciente relevancia del discurso de los derechos constitucionales y de los tribunales en la vida política es un fenómeno casi universal ${ }^{8}$. Sin embargo, en algunas naciones de Europa Continental (Alemania, Italia, y España) y Latinoamérica, aquella evolución del derecho constitucional ha seguido derroteros específicos. Por una parte, este fenómeno reflejaría la aparición de constituciones rígidas con un claro contenido axiológico, en el que los derechos fundamentales son vistos como valores que irradian todo el ordenamiento y la sociedad, los que deben ser aplicados directamente por los jueces. Adicionalmente, en sus visiones más amplias, este fenómeno también abarcaría la incorporación de los derechos

\footnotetext{
Aldunate (2010). Para un debate al respecto ver Bernal Pulido (2007).

${ }^{6}$ Carbonell (2003); Prieto Sanchís (2010).

Pozzolo (1998); Comanducci (2002); Carbonell (2007). Prieto Sanchís (2010).

8 Hirschl (2007); Tate y Vallinder (1997).
} 
humanos consagrados en tratados internacionales, los que, a su vez, habrían sido integrados a los ordenamientos internos por las mismas constituciones?

A través del tiempo, esta trasformación ha prefigurado un verdadero cambio de paradigma que involucra a toda la cultura jurídica. Es habitual que este sea descrito como un paso desde el estado legal de derecho vinculado al positivismo jurídico -en auge a mediados del siglo XIX-, hacia uno nuevo llamado estado constitucional de derecho, surgido gradualmente a fines del siglo $\mathrm{XX}^{10}$. Los orígenes de este cambio de paradigma son variados. Entre ellos podemos destacar el establecimiento de tribunales constitucionales y procedimientos de judicial review con posterioridad a la segunda guerra mundial y a gobiernos autoritarios, en particular en Europa Continental y Latinoamérica. También ha incidido el prestigio de la Corte Suprema de los Estados Unidos ${ }^{11}$. Desde comienzo de la década de 1980, la expansión del catálogo de garantías constitucionales en conjunto con la consolidación del sistema democrático ha tenido asimismo un rol central ${ }^{12}$. En último lugar, podríamos agregar toda una corriente académica transnacional que describe los últimos desarrollos del constitucionalismo, basada en autores como Ronald Dworkin y Robert Alexy ${ }^{13}$.

Por otra parte, a nivel teórico, esta transformación habría sido defendida por algunos académicos, quienes describen este proceso de constitucionalización y buscan promover su desarrollo ${ }^{14}$. Siguiendo a los autores quienes describen este fenómeno -antes citados-, es posible entregar algunas formulaciones básicas del neoconstitucionalismo a nivel teórico: a) la centralidad de las garantías fundamentales en el razonamiento jurídico, b) el énfasis en los conflictos de principios (o derechos) que deben ser resueltos mediante la ponderación judicial, c) el escepticismo sobre la suficiencia de la ley, y su consiguiente subordinación bajo los valores constitucionales, d) la explícita incorporación de elementos morales en el razonamiento propio de la interpretación constitucional, y e) un énfasis en la justicia substantiva, entre otros ${ }^{15}$.

A nivel de los compromisos teóricos, diversos autores suelen ser asociados con el neoconstitucionalismo, aun cuando varios de ellos no hayan aceptado esta denominación. Estos constituyen una larga cadena compuesta por productores teóricos de mayor envergadura intelectual, receptores académicos locales y una versión popular que adolece de cierto grado de vulgarización ${ }^{16}$. Algunos autores que presentan una mayor sofisticación teórica se encuentran en el primer eslabón. Tal es el caso de Robert Alexy, Peter Häberle y los primeros textos de Ronald Dworkin (aunque este último pertenece a la tradición jurídica anglosajona, se ha convertido en un punto de referencia significativo dentro de esta corriente) ${ }^{17}$.

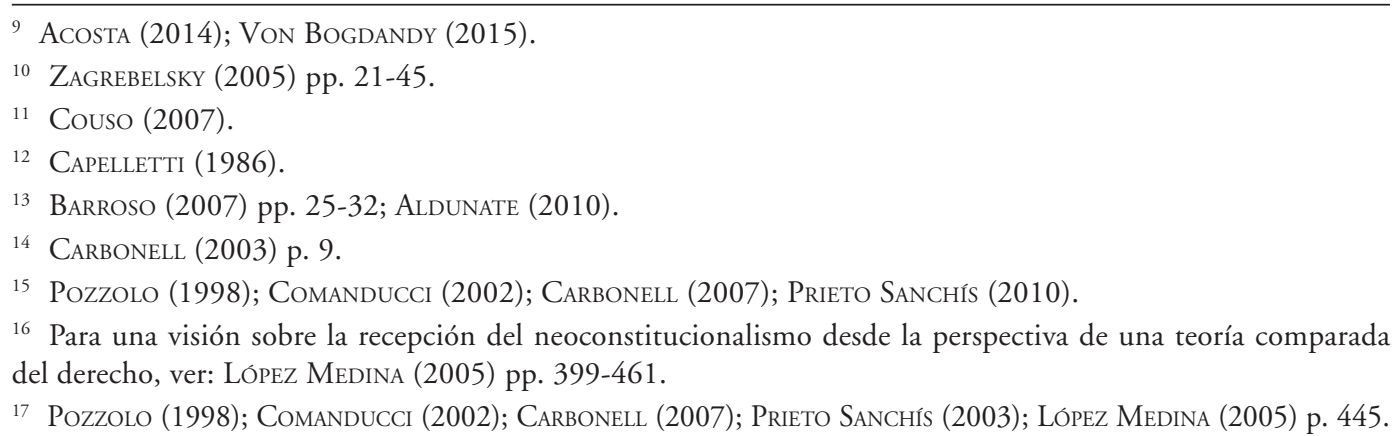


Desde análisis más particulares, también destacan otros como Gustavo Zagrebelsky o Luis Prieto Sanchís ${ }^{18}$. En el segundo eslabón dentro de esta cadena, se encuentran numerosos receptores académicos locales y algunos jueces que han tomado las banderas del estado constitucional de derecho como una manera de reclamar autoridad. Entre estos podríamos destacar a Carlos Gaviria en Colombia, Luis Roberto Barroso en Brasil y Eduardo Ferrer Mac-Gregor en México ${ }^{19}$.

Esta corriente transnacional no constituye un movimiento intelectual de jueces y juristas que se halle claramente cohesionado. Además de sus diversos grados de sofisticación académica, es posible observar que en estos autores existe un amplio espectro de afinidades intelectuales. Ellas pueden ser complementarias a las ideas matrices del neoconstitucionalismo, pero nada obsta a que existan tensiones. Algunos de ellos pueden además estar influidos por la nueva retórica, el garantismo penal, el iusnaturalismo católico e, inclusive, el uso alternativo del derecho ${ }^{20}$. Así, el neoconstitucionalismo no posee un programa político definido. Aunque habitualmente se ha asociado a esta corriente con una agenda propia del liberalismo, también hay algunos conservadores que la han promovido como una forma de limitar la omnipresencia del estado.

Es posible afirmar que la hipótesis del juez racional cumple un papel central dentro de este fenómeno, articulando sus elementos más importantes, como la aplicación directa de los derechos fundamentales o la resolución de conflictos mediante la ponderación. Ello ocurre aun cuando, muchas veces, los autores vinculados a este fenómeno no describan a los magistrados de manera directa. Tal como la dogmática positivista adhirió oblicuamente al legislador racional, refiriéndose a la idea de sistema jurídico, quienes sostienen este nuevo paradigma describen a este modelo juez a través del concepto de estado constitucional de derecho.

\section{LOS ATRIBUTOS DEL JUEZ RACIONAL}

La sección anterior ha definido al neoconstitucionalismo como un fenómeno de ribetes difusos. Asimismo, ha propuesto que este se encuentra en buena manera articulado por una cierta visión idealizada de las magistraturas, al que este artículo ha denominado el modelo del juez racional. Pero en concreto ¿qué atributos se han asignado a esta figura hipotética?

\section{1. Órgano que resuelve el CONFlicto político mediante una deliberación RACIONAL, CORRECTA Y SUFICIENTE PARA PERSUADIR A LA CIUDADANÍA}

A diferencia de lo ocurrido a comienzos del siglo XIX, cuando las elites confiaban en la infalibilidad de la voluntad soberana en el proceso legislativo, las últimas décadas han estado caracterizadas por el signo exactamente opuesto. La mayoría de los autores neoconstitucionalistas inician su reflexión desde el escepticismo, desconfiando de que el legislador sea capaz de producir normas claras que expresen racionalmente intereses objetivos. Asi-

\footnotetext{
18 Carbonell (2003) p. 9.

19 Gaviria díaz (2002); Barroso (2016); Ferrer Mac-Gregor (2010).

20 Ver, por ejemplo: Prieto Sanchís (2011).
} 
mismo, describen a la legislación como un conjunto caótico de normas, caracterizado por ambigüedades y vacíos. Tal situación sería producto de la creciente confrontación política en las sociedades contemporáneas, la que no habría podido ser mitigada por los tradicionales métodos del positivismo jurídico ${ }^{21}$. "La Ley [...] ya no es la expresión pacífica de una sociedad política internamente coherente, sino que es manifestación e instrumento de competición y enfrentamiento social; no es el final, sino la continuación de un conflicto [...]" puntualiza Gustavo Zagrebelsky, ex presidente de la Corte Constitucional italiana ${ }^{22}$.

Como alternativa, el neoconstitucionalismo tiende a exaltar la figura del juez, afirmando que este sería responsable de corregir el proceso político a través de una deliberación racional que integre la voluntad democrática, de carácter contingente, con los valores constitucionales. Siguiendo esta línea de análisis, algunos de los autores que adhieren a esta corriente describen el razonamiento judicial de manera ficticia, atribuyéndole la capacidad cierta de persuadir a los ciudadanos que abracen los valores constitucionales. Tal es el caso de la justificación que Robert Alexy ofrece para legitimar el judicial review.

Según Alexy, el Congreso sería un espacio para la actividad decisional, en el que el poder político puede debatir y ejercer su voluntad. Los tribunales, por el contrario, poseerían una representación del pueblo para realizar una labor puramente argumentativa ${ }^{23}$. Para efecto de fundar aquel carácter representativo de los magistrados, Alexy propone dos condiciones copulativas.

En primer lugar, él considera que los tribunales deben deliberar recurriendo a argumentos constitucionales correctos, o al menos plausibles, distinguiéndolos de aquellos que no lo son ${ }^{24}$. Siguiendo a Habermas, Alexy asume que la racionalidad es una construcción intersubjetiva que reposa sobre el orden y justificación de las premisas utilizadas en el proceso de diálogo. No es extraño, entonces, que él defina a la argumentación jurídica como un tipo de discurso práctico que debe tener reglas mínimas de carácter universal, autónomas respecto de aquello que es debatido. Para este propósito, Alexy desarrolla un sofisticado esquema destinado a mantener el orden argumentativo, el que establece reglas tanto para fundamentar la selección de las premisas a utilizar como para mantener la corrección lógica del diálogo. Esta ordenación del discurso práctico haría posible expurgar las afirmaciones equívocas, determinar argumentos razonables y persuadir a los intervinientes ${ }^{25}$.

En segundo lugar, Alexy afirma que los jueces no gozarían de un carácter representativo meramente por tomar decisiones procedimentalmente correctas, sino porque además tales decisiones deberían ser aceptadas en el largo plazo por un número suficiente de personas dispuestas a ejercer sus capacidades racionales ${ }^{26}$. Esto es, por individuos orientados a considerar las razones de la decisión en sí mismas, obviando sus propios intereses que

\footnotetext{
21 Fioravanti (1996) pp. 127- 129; Prieto Sanchís (1998) pp. 5-46; Barroso (2016).

22 Zagrebelsky (2005) p. 38.

23 Alexy (2005) p. 579.

24 Alexy (2005) p. 580; Alexy (2015): pp. 442-443.

25 Alexy (2007).

26 "The existence of good or plausible arguments is enough for deliberation or reflection, but not for representation. For this, it is necessary the court not only claim that its arguments are the arguments of the people; a sufficient number of persons must, at least in the long run, accepts these arguments for the reasons of correctness". AlEXY (2005) p. 580.
} 
pudieren estar involucrados. A ellos les llama ciudadanos constitucionales ${ }^{27}$. Así, la carencia de una selección electoral de los jueces no sería óbice para su legitimidad democrática, pues los ciudadanos comprometidos con los valores constitucionales deberían aceptar las respuestas correctas que los jueces determinen.

Esta descripción de un juez racional, erigido en una especie de guía tutelar de la deliberación pública, no ha permanecido únicamente dentro de los círculos académicos. Con matices, lentamente esta ha comenzado a influir la propia autopercepción de los magistrados $^{28}$. Eduardo Ferrer Mac-Gregor, ex -ministro de la Corte Suprema de México y actual Presidente de la Corte Interamericana de Derechos Humanos, explicaba durante la audiencia frente al Senado de su país previa a su primer nombramiento: "La legitimidad de la interpretación judicial de la Constitución no solo proviene de una férrea e implacable argumentación racional. El juzgador constitucional debe buscar que sus decisiones sean en realidad persuasivas para los ciudadanos y que estos se formen un consenso sobre el sentido que dan a la Ley Fundamental" 29 .

La tesis antes descrita ofrece una serie de elementos que permiten calificarla como una ficción. El proceso de argumentación racional caracterizado por Alexy puede ser un buen ejercicio intelectual, pero no es una constatación empírica del proceso de argumentación judicial. Los magistrados usualmente poseen desacuerdos sobre cuestiones básicas del razonamiento, partiendo por los términos de interpretación de los textos constitucionales (por ejemplo, el debate sobre originalismo y constitución viviente) ${ }^{30}$. Ello también ocurre respecto de los ciudadanos comunes, para quienes muchas de las reglas de argumentación propuestas por Alexy resultarían incomprensibles.

Asimismo, pareciera que la descripción propuesta ignora la posibilidad permanente del error judicial en materias constitucionales. Tal como plantea Alexy, desde el punto de vista interno, los magistrados buscan alcanzar decisiones correctas que aludan a argumentos jurídicos razonables ${ }^{31}$. No obstante, a nivel comparado, existe un sinnúmero de sentencias que hoy son citadas como arquetipos de un razonamiento equívoco por la doctrina, la jurisprudencia posterior e inclusive por la opinión pública. Es posible que los jueces decidan en innumerables ocasiones con acierto, pero también la sociedad admite que en algunas otras ellos cometen errores. Por ello, una pretendida capacidad de tomar decisiones correctas desde el punto de vista constitucional no puede constituir la base de la representación que él les asigna a los tribunales constitucionales para intentar legitimar el judicial review.

En último lugar, cabe agregar que Alexy minimiza los problemas de desacuerdo que son comunes en las sociedades democráticas contemporáneas. Aun cuando él reconoce un

\footnotetext{
27 Alexy (2005) p. 580. El papel pedagógico de la jurisdicción constitucional sobre la ciudadanía puede también ser encontrado en otros autores dentro de esta corriente. HäBErle (1997). pp. 240-245. También puede hallarse en la descripción que John Rawls realiza de la Corte Suprema de su país como ejemplo paradigmático de la razón pública. Sin embargo, en este último caso Rawls refiere un modelo ejemplar que posee limitaciones, no como una ficción universalizable. RaWLS (2005). 231-240.

28 ZaGRebelsky (2007) p. 99.

29 Ferrer Mac-Gregor (2010) p. 16.

30 Ely (1980) pp. 11-72. Waldron (1999) p. 306.

31 Alexy (2015).
} 
ámbito relativamente discreto para el ejercicio para el judicial review, y plantea distintas situaciones en que el juez debe ser deferente con la autoridad política, tal problema permanece abierto ${ }^{32}$. Su descripción de los ciudadanos constitucionales es un asunto que resulta difícil de aceptar como una realidad. En muchos de los conflictos que hoy son sometidos a la jurisdicción constitucional existe una confrontación entre ciudadanos razonables que creen poseer argumentos plausibles (como en los casos del aborto o el matrimonio homosexual). No existe ninguna garantía que permita sostener que, por si mismos, los argumentos entregados en las decisiones judiciales sean superiores a los de quienes abogan por la sentencia en la dirección opuesta, o que puedan persuadir a una generalidad de la población que genuinamente crea en los valores incorporados en la constitución ${ }^{33}$. Alexy describe a los jueces asumiendo que ellos son una expresión de la razón institucionalizada, a fin de fundar lo que él denomina un constitucionalismo discursivo. No obstante, su idealización resulta ficticia.

\section{2. ÓrganO ENCARGADO DE UNA ESPECIAL REPRESENTACIÓN POLÍTICA NO DELEGADA}

La obra de Alexy, y de algunos otros autores locales que le han seguido de cerca, no solo enfatiza la capacidad de deliberación racional de los jueces. Intentando responder a su eventual carácter contra-mayoritario, adicionalmente sostienen que los tribunales cumplen un verdadero papel de representación política. Según hemos visto, aquella representación se encontraría fundada principalmente en la capacidad de los magistrados para tomar decisiones correctas y por la aceptación de estas últimas entre los ciudadanos racionales ${ }^{34}$. De este modo, Alexy asume el rol judicial dentro de del marco de una democracia deliberativa.

En el planteamiento seguido por Alexy, los jueces son representantes para realizar una labor puramente argumentativa, es decir, de reflexión racional. Ello sería posible porque la democracia no sería un procedimiento en el que meramente se cuentan los votos en las elecciones y en el parlamento. Adicionalmente, esta consistiría en un régimen legitimado por las razones que se expresan en el proceso de toma de decisiones ${ }^{35}$. Desde tal perspectiva, la corte constitucional sería una especie de guardián que custodia que tal debate se produzca de una manera libre, abierta y, por sobre todo, con argumentos aceptables desde el punto de vista de la carta fundamental.

Al realizar esta afirmación, Alexy recurre a un concepto laxo de representación, que difiere de ser un mero mandato en el que los representantes políticos reciben una delegación de facultades mediante el sufragio electoral. Al hacerlo, él no se limita meramente a señalar que los jueces realizan una labor en nombre del pueblo, como cualquier autoridad republicana. La representación judicial descrita por Alexy consistiría en una autoridad vali-

\footnotetext{
32 Alexy considera que en ciertas situaciones los derechos fundamentales no obligan algún particular curso de acción (discrecionalidad estructural). En otros casos, él sugiere la deferencia respecto del legislador cuando existe incertidumbre sobre la información empírica relativa al caso, o sobre la mejor ponderación de los derechos fundamentales en juego (discrecionalidad epistémica) ALEXY (2010a) pp. 394-426. Sin embargo, estos aspectos no alteran la tesis central sobre el carácter representativo de los jueces constitucionales, antes descrita.

33 Kumm (2012) p. 208.

34 Alexy (2005) p. 580; Alexy (2010b) pp. 35-37.

35 Alexy (2005) pp. 578-579.
} 
dada ex post. Más allá de los mecanismos de designación de los magistrados, su legitimidad nacería cuando estos dictaminan sentencias correctas que son posteriormente aceptadas por ciudadanos racionales y desinteresados. Se trataría, asimismo, de una representación que opera primariamente por identidad, en la medida que los ciudadanos ven reflejado un concepto mínimo y compartido de justicia en las decisiones judiciales correctas. En este ámbito, la representación consistiría en un vínculo análogo al que se produce entre la comunidad y un símbolo patrio o una tradición arraigada, aunque fundamentado en la reflexión racional sobre los valores constitucionales. Finalmente, se trataría de un tipo de legitimidad orientado hacia el mejor interés del régimen democrático ${ }^{36}$.

Aun cuando aceptáramos una noción laxa de representación política, es posible sostener que la tesis propuesta por Alexy se desenvuelve dentro del marco de una ficción sobre el rol del juez y/o su relación con la comunidad política. A las críticas ya analizadas en el acápite anterior sobre la corrección del razonamiento judicial, se deben sumar otras referidas específicamente sobre este punto.

En primer lugar, de que los ciudadanos acepten tal o cual decisión de la corte por considerarla correcta, no puede deducirse el carácter políticamente representativo de la autoridad judicial para revisar la legislación. Habitualmente los ciudadanos poseen opiniones que son contradictorias y variadas en las más diversas materias. Es de esperar que solo estén en acuerdo con algunas de las cuestiones resueltas por la corte constitucional, pese a que otras les parezcan objetables. Así, mientras el vínculo de los ciudadanos con las decisiones opera de manera parcial y múltiple, el carácter representativo que Alexy alega recae sobre la competencia misma del tribunal en su totalidad. La única manera de salvar este escollo teórico sería sostener que los ciudadanos racionales aceptarían la generalidad de las decisiones de la corte. Es decir, nuevamente recurriendo a una ficción sobre la capacidad persuasiva de los jueces y la unidad de criterio sobre el alcance de los valores constitucionales.

En segundo lugar, parece ficticio sostener -como lo hace Alexy-, que una representación que opera ex post sea el fundamento de las facultades de judicial review. Para que la representación que alega Alexy se verifique, la decisión del tribunal debe ser pronunciada y luego, aún en el largo plazo, aceptada por ciudadanos racionales como una decisión correc$\mathrm{ta}^{37}$. Aun cuando Alexy alegue que los jueces son capaces de alcanzar respuestas correctas, él sitúa el pivote central del fundamento para ejercer esta competencia en un resultado incierto: la aceptación de la ciudadanía en el ejercicio de sus capacidades racionales. Ello equivaldría a señalar que se autoriza al juez para resolver un determinado conflicto una vez que consideramos que su decisión es aceptable, viéndonos reflejados en aquella sentencia. Nada de aquello ocurre en la realidad política. Habitualmente, los litigantes esperan que las facultades del tribunal estén legitimadas antes de que este conozca del conflicto. Asimismo, es usual que una vez comunique la sentencia surjan controversias respecto a si ella es o no correcta, tanto entre los académicos como entre la ciudadanía ${ }^{38}$. No existe un claro motivo

\footnotetext{
36 Para una tipología sobre la representación, ver PITKIN (1972).

37 Alexy (2005) p. 580; Kumm (2012) p. 206.

38 Una manera de intentar salvar esta objeción podría plantearse afirmando que el tribunal puede construir su autoridad a lo largo del tiempo, mediante distintas decisiones que acumulen legitimidad. Sin embargo, Robert Alexy no plantea aquella línea de análisis.
} 
para sostener que la teoría de legitimación ex post debería preferir a una que opere ex ante, como la autolimitación del poder político a través de la creación de un tribunal cuyos miembros son seleccionados por las autoridades democráticas.

Para algunos quienes adhieren a la tesis de Alexy, la idea de representación argumentativa no involucra solamente una explicación sobre el lugar de los jueces en el diseño institucional. En una lectura que va bastante más allá de la tesis original, también significa un juicio de sospecha respecto de la democracia representativa. Tal es el caso de Luis Roberto Barroso, juez del Supremo Tribunal Federal de Brasil. Para Barroso, el rol representativo del juez ha surgido en un contexto en que existe una crisis integral de la democracia, caracterizada por la corrupción, la captura de los organismos públicos por intereses privados, y por una alta abstención electoral ${ }^{39}$. Como consecuencia, la democracia representativa poseería graves dificultades para expresar la voluntad mayoritaria de la población. En esa encrucijada, Barroso plantea que paradójicamente "en muchas situaciones jueces y tribunales se hicieron más representativos de los anhelos y demandas sociales que las instancias políticas tradicionales. Es raro, pero vivimos un momento en que la sociedad se identifica más con sus jueces que con sus parlamentarios" ${ }^{30}$.

\section{INTÉRPRETES DE LA MORALIDAD PÚBLICA MEDIANTE LA RECONSTRUCCIÓN DE LA INTEGRIDAD DEL SISTEMA JURÍDICO}

Ronald Dworkin ha seguido una dirección distinta para responder al supuesto carácter contra-mayoritario de la actividad judicial, enfatizando la habilidad del magistrado para interpretar la moralidad pública y sus relaciones con el sistema jurídico. Aunque la teoría propuesta por Dworkin posee algunos puntos de encuentro con las tesis ya estudiadas -como una superlativa capacidad de razonamiento del juez-, se trata de una aproximación diferente, que requiere un examen particular.

Dworkin planteó una crítica al positivismo jurídico anglosajón dominante en la década de 1970, el que afirmaba que los jueces creaban discrecionalmente derecho en situaciones de vacíos o ambigüedades legislativas (casos difíciles). Él estima que tal tesis sobre la creación judicial, representada por H. Hart, no resultaba aceptable por ser contraria al sistema democrático y por constituir una aplicación retroactiva de las normas ${ }^{41}$. Como alternativa, afirma que en aquellos casos los jueces no crean derecho, sino que descubren respuestas correctas cuyos fundamentos ya están incorporados en el sistema jurídico. Al hacerlo, Dworkin propone que el ordenamiento no solo está compuesto de reglas que buscan ser aplicadas mecánicamente, sino que también por directrices que establecen objetivos socioeconómicos y por principios de justicia que describen derechos subjetivos ${ }^{42}$. Aunque más abstractos, estos resultarían esenciales para comprender como los tribunales dirimen conflictos que no pueden ser solucionados por la mera aplicación de reglas.

\footnotetext{
39 Barroso (2016) pp. 148-150.

40 Barroso (2016) p. 148.

41 Dworkin (1977) pp. 84-85; SHAPIro (2011) pp. 263-264.

${ }^{42}$ Dworkin (1977) pp. 22-31.
} 
De entre todos los componentes del orden jurídico, los principios (derechos) deben prevalecer por sobre los demás, pues encarnarían razones de justicia que se hayan por sobre consideraciones de mera utilidad social. Los derechos constituyen decisiones políticas fundamentales adoptadas en el pasado, que han sido integradas a la vida social y que el juez debe considerar en su toma de decisiones para ser consistente con la integridad del sistema jurídico ${ }^{43}$. El problema, sin embargo, es que los casos difíciles habitualmente no solo carecen de una regla a aplicar mecánicamente. Asimismo, ellos muchas veces enfrentan litigantes que fundan sus pretensiones en derechos subjetivos que resultan contradictorios.

Para resolver aquellos casos, Dworkin propone la figura del juez Hércules, el que debe poseer virtudes activas para interpretar los compromisos morales de la comunidad, permitiéndole descubrir una única respuesta correcta. Esta figura judicial arquetípica no actúa en el vacío, sino dentro de una comunidad interpretativa que posee una cierta visión sobre los vínculos y obligaciones compartidos, la que, desde dentro, él mismo ayuda a construir ${ }^{44}$. Así, en materias constitucionales, la jurisdicción debe interpretar el texto fundamental de acuerdo a principios morales sobre una vida decente y la justicia al interior de aquella comunidad ${ }^{45}$.

Ante la titánica tarea de poder resolver casos difíciles ponderando derechos contrapuestos, el juez Hércules debe encontrar la respuesta correcta a través de su habilidad reflexiva. Pero aquello en ningún caso significa que él pueda esgrimir sus propias preferencias o aludir la mera opinión popular en un momento determinado, pues estas podrían estar en contraposición con la moralidad constitucional. Tampoco significa equiparar al juez con la figura del legislador, como plantea el positivismo jurídico de Hart al tratar la respuesta judicial a los vacíos normativos ${ }^{46}$. Por el contrario, Dworkin sostiene que el juez posee la capacidad de refinar la moralidad pública, tanto la que se encuentra contenida en la constitución como a nivel social, expurgándola de prejuicios y reacciones emocionales, re-articulándola de manera consistente con la totalidad el sistema legal ${ }^{47}$.

Para ilustrar su argumento, Dworkin sostiene que el juez Hércules es como un escritor que continúa una novela inacabada iniciada por otros autores en el pasado. Al tomar la posta en aquella sucesión, él debe considerar cuidadosamente los fragmentos anteriores interpretándolos de la mejor manera posible. En este nuevo capítulo, el juez debe agregar su propia contribución, pero desenvolviendo los materiales previos de manera coherente para que el argumento central fluya. Esto implica que él debe prolongar la novela de forma plausible, pero, al mismo tiempo, hacerlo de una manera sugestiva para los nuevos lectores. Quizás, durante su proceso de escritura, podrán elaborarse diversos borradores del nuevo capítulo, narrando varios relatos posibles. Pero siempre habrá uno que finalmente será el más consistente y atractivo considerando el contenido íntegro de la obra ${ }^{48}$.

43 DWORKIN (1977) pp. 87. 94.

44 Dworkin (1977) pp. 126-128; CotTERrell (1992) pp. 173-177.

45 DwORKIN (1996).

46 DWORKIN (1986) p. 244.

47 Dworkin (1977) pp. 126. 240-258.

48 Dworkin (1986) pp. 228-238. 
Un buen ejemplo de la labor del juez Hércules es la explicación que él ofrece retrospectivamente sobre Brown v Board of Education, que en 1954 terminó con la segregación racial en las escuelas. La Constitución de los Estados Unidos, en su enmienda décimo cuarta sobre la igual protección, no fue redactada originalmente con la intención de ser aplicada a la población afroamericana. Los miembros de este grupo racial no fueron considerados ciudadanos hasta varias décadas más tarde, existiendo posteriormente un régimen de tolerancia respecto a su discriminación. Así, tanto la legislación de los estados como la jurisprudencia de los tribunales reconocían la posibilidad de mantener escuelas racialmente segregadas. Sin embargo, distintos aspectos del derecho y la opinión pública variaron hacia este período. La sociedad lentamente asumió que ciertas categorías, como la raza, no debían ser permitidas para efectos de fundar discriminaciones negativas (al fin y al cabo, el antisemitismo era una de las razones por las cuales el nazismo -recientemente combatido por su país-, parecía inaceptable). Del mismo modo, la jurisprudencia de los tribunales había dejado atrás la neutralidad que reconocía cualquier tipo de preferencia social como lícita. Por ello, habían aparecido numerosos precedentes rechazando situaciones de discriminación fundada en prejuicios, especialmente cuando estos se referían a grupos históricamente desventajados. Tales discriminaciones eran consideradas sospechosas de trasgredir la cláusula de igual protección, siendo necesario justificar cuidadosamente su licitud. Hacia 1954, al juez Hércules correspondía reconsiderar este asunto. Siguiendo la alegoría de la novela inacabada, debía escribir otro capítulo considerando materiales adicionales y una nueva audiencia. La única respuesta correcta era la prohibición de la segregación racial en las escuelas, aun cuando ello no fuere intención de la constitución original, aun cuando tal solución resultara contrapuesta a algunos precedentes previos, y aun en contra de la opinión de ciertos grupos minoritarios que resistían esta medida. Según Dworkin, solo cabía una forma de ser consistente con la integridad del sistema jurídico y la moralidad pública ${ }^{49}$.

El juez Hércules, antes descrito, no es solo una teorización de la alta filosofía jurídica. En Europa Continental y Latinoamérica, este se ha convertido en parte del discurso de magistrados y académicos que han buscado expandir la autoridad judicial. Por ejemplo, esta tesis puede observarse en los textos de Zagrebelsky, quien plantea que los jueces no solo deben aplicar la ley, sino que deben recoger la red de vínculos jurídicos que componen todo el derecho (incluyendo los principios constitucionales con todas sus implicancias axiológicas $)^{50}$. Igualmente, abundantes referencias a la teoría de Dworkin pueden encontrase en la jurisprudencia de la Corte Constitucional Colombiana desde la década de $1990^{51}$.

La figura de un juez omnisciente con la habilidad de descifrar, e incluso perfeccionar, la moralidad pública, sin duda constituye una ficción. Resulta difícil imaginar un magistrado con la sabiduría, método y ecuanimidad para reconstruir consistentemente el derecho y la moralidad pública, hallando una única respuesta correcta ante cada caso difícil. Sin duda los jueces son individuos altamente adiestrados en los laberintos de la dogmática jurídica, pero la mayor parte de ellos poseen un bajo entrenamiento para elaborar juicios propios de

\footnotetext{
49 Dworkin (1986) pp. 379-389.

50 Zagrebelsky (2005) pp. 116-120. 151-153.

51 López Medina (2005) pp. 445-452.
} 
la ética ${ }^{52}$. También parece inverosímil aceptar que el magistrado sería capaz de purificar los compromisos morales de la comunidad sin que, en el intento, imponga aun de forma inconsciente sus propias preferencias. El juez Hércules puede ser persuasivo como una figura propia de la gran teoría del derecho, pero difiere de los jueces reales.

Sin embargo, lo que resulta más complejo aún, es que la tesis propuesta por Dworkin es doblemente ficticia. Junto con exaltar la figura del juez, también idealiza los compromisos morales de la comunidad y/o la consistencia del sistema jurídico. Al sostener esta posición, esta minimiza los desacuerdos propios de las sociedades contemporáneas, los que se han agudizado como parte del proceso de modernización. Existen innumerables situaciones donde las normas jurídicas y las prácticas sociales se encuentran en contradicción, especialmente respecto de cuestiones que son altamente divisivas para la sociedad ${ }^{53}$. Inclusive, sería posible sostener que un significativo número de directrices y principios de textura abierta dentro del ordenamiento jurídico poseen importantes grados de indeterminación porque no existe un compromiso bien definido respecto de sus consecuencias y alcance. Podemos fácilmente llegar a un acuerdo sobre el principio de igualdad ante la ley, pero sus eventuales consecuencias en lo relativo a los discapacitados, homosexuales, no-nacidos, o inversionistas extranjeros serán mucho más controversiales. Los aludidos compromisos morales de la comunidad no siempre serán identificables.

\section{Agentes capaces de CONOCER DE MANERA DiReCta las PREFERENCias MORALES DE}

LA CIUDADANÍA Y LA REALIDAD SOCIAL

Varios autores locales han ido más allá de la teoría de Dworkin, enfatizado la figura del juez como un actor capaz de leer directamente las preferencias morales de la comunidad y la realidad social, sin necesariamente desplegar una teoría compleja en relación con la consistencia del sistema jurídico. Esta lectura más radical del papel del juez debe entenderse como una reacción al positivismo jurídico que dominó Europa Continental y Latinoamérica hasta hace unas décadas. Caracterizados por una aproximación meramente dogmática, los tribunales fueron acusados de una profunda desconexión con la sociedad y de no dar respuesta a los problemas de su tiempo (por ejemplo, la lentitud en el cambio de las instituciones y la violencia política). En cierto modo, el neoconstitucionalismo fue una de las respuestas que encauzó aquellas críticas. Por ello, parte de esta corriente ha reivindicado el restablecimiento del vínculo directo entre el juez y la sociedad.

Existen innumerables autores que emplean esta figura retórica con diversos énfasis. Algunos han sostenido que "el objetivo de la actividad jurisdiccional [es] la realización de los valores jurídicos socialmente dominantes", tal como afirmaba hacia 1989 Jorge Correa Sutil, quien más tarde llegaría a ser miembro del Tribunal Constitucional de Chile ${ }^{54}$. Este rol del magistrado como intérprete de la realidad social aparecería, por ejemplo, frente a casos en que existan lagunas o aplicación de estándares que requieren de una referen-

\footnotetext{
52 Yowell (2018) pp. 104-113.

53 ELY (1980) pp. 63-69.

54 Correa Sutil (1989) p. 305. Es necesario reconocer, sin embargo, que esta lectura del rol judicial ha sido abandonada por Correa Sutil en los años recientes.
} 
cia a elementos externos al sistema jurídico para su concreción. Entre otros, esta última aproximación ha sido defendida por Francisco Rubio Llorente, exministro del Tribunal Constitucional español ${ }^{55}$. Al explicar los distintos presupuestos que permiten calificar si una discriminación establecida por la ley es o no constitucionalmente aceptable, Rubio Llorente afirmaba: "el poder del juez, como todo poder del Estado democrático, deriva exclusivamente de la comunidad, y solo en la conciencia jurídica de la comunidad puede buscar el juez el criterio que le permita pronunciarse sobre la razonabilidad [...] de la obra del legislador" 56 .

La posición de Luis Roberto Barroso, citado más arriba en relación con el rol de representación política que detentarían los jueces, constituye una buena ilustración de una lectura más radical de esta capacidad judicial. Según Barroso, los sistemas de reclutamiento y las garantías a su independencia permitirían que los magistrados pudieran interpretar las preferencias mayoritarias de la población sin que interfieran los obstáculos que afectan a la democracia representativa. Una amplia lista de fallos judiciales, como los referidos a la desegregación racial de escuelas en los Estados Unidos o la garantía de acceso a los medicamentos para el VIH en Brasil, comprobaría que en innumerables ocasiones los jueces atienden demandas sociales insatisfechas ${ }^{57}$. Inclusive, para Barroso, correspondería a los jueces cumplir el papel de "una vanguardia iluminista", encargada de empujar procesos de cambio $^{58}$. Ello sería posible porque, "basado en materiales jurídicos, [...correspondería al juez] interpretar el sentimiento social, el espíritu de su tiempo, y el sentido de la historia. Con la dosis correcta de prudencia y osadía" 59 .

La capacidad de los jueces para interpretar directamente la realidad social evidentemente constituye un atributo ficticio. Cualquier persona que posea un conocimiento mínimo en ciencias sociales entiende las dificultades de una observación empírica. Sin embargo, quienes sostienen este atributo no están pensando en las complejidades de la inferencia causal, en el descarte de hipótesis competitivas, o en la codificación de datos para efectos de su diferenciación al momento de observar los hechos. Tampoco se estarían refiriendo a la opinión de peritos. Se trataría de una capacidad intuitiva que tendría el juez para formarse una opinión acabada de la realidad social. Sin embargo, la competencia de los magistrados -como la de todas las personas que poseen formación únicamente en ciencias jurídicas-, tiene importantes limitaciones a este respecto. Solo cabe reconocer que ellos se encontrarían en desventaja frente a las agencias administrativas y la legislatura, compuestas por personas que poseen distintos bagajes epistemológicos ${ }^{60}$.

Además de las limitaciones para conocer la realidad social, se agregan otras relacionadas con la capacidad de los jueces para interpretar los sentimientos morales de la comunidad. Según ha sido analizado anteriormente, una de las objeciones a este punto es que

\footnotetext{
Prieto Sanchís (1991) p. 176.

6 Rubio LLorente (1991) p. 32.

BARroso (2016) pp. 158.164.

BARroso (2016) pp. 155.

BARroso (2016) pp. 164.

Yowell (2018) pp. 68-73. 98-104.
} 
esta habilidad presupone que tales sentimientos homogéneos a nivel social existan y que el magistrado pueda aplicarlos sin sustituirlos por sus propias preferencias. También resulta problemático explicar cómo, de existir aquel ethos, este podría ser conciliado con la protección de las minorías.

\section{5. Órganos ImParciales QUe SE ENCUENTRAN POR SOBRE EL PROCESO POlítico}

Bajo diversas líneas de observación, la imparcialidad es otro de los atributos que constituyen el modelo de juez racional. Es casi un lugar común afirmar que los tribunales, por razones de diseño institucional, están en mejores condiciones de arbitrar casos de conflicto político o tutelar los derechos fundamentales. Por ejemplo, los jueces usualmente no son seleccionados por sufragio popular directo y no pueden ser removidos de sus cargos de manera expeditiva por el gobierno de turno. De acuerdo a ciertos autores dentro de esta corriente, como Luis Roberto Barroso, estos atributos les habilitarían para actuar de manera más ecuánime y resolver sobre asuntos que trascienden la política contingente recurriendo a los principios constitucionales ${ }^{61}$. A esta explicación sobre la imparcialidad judicial también se agregan otras. Para algunos, dicho atributo nacería en función de lo que el juez debe resolver: la constitucionalidad. En aquella perspectiva, Zagrebelsky plantea que los órganos políticos democráticos deciden sobre lo que se vota, mientras que, por el contrario, los jueces constitucionales poseen un rol distinto, de carácter republicano, orientado sobre aquello que no se vota ${ }^{62}$. Para otros, como Häberle, la apertura pluralista del tribunal a todos los intereses le permitiría participar de la actualización de la carta fundamental como contrato social, en conjunto con la ciudadanía ${ }^{63}$. Ninguno de estos autores asevera que los jueces posean una imparcialidad absoluta. No obstante, ellos invitan a asumir teóricamente que los magistrados se encuentran por sobre el proceso político ordinario, minusvalorando el problema que ofrecen sus preferencias políticas personales y los incentivos institucionales.

No resulta sorprendente que el neoconstitucionalismo, el cual de forma significativa descansa en rol desempeñado por el juez, enfatice la imparcialidad de este último. El motivo se halla en la organización misma de la jurisdicción. De manera universal, la lógica básica del tribunal está constituida por la triada en que un tercero resuelve una disputa entre dos litigantes contradictores. Al momento de la sentencia, esta triada corre el riesgo perder su legitimidad y desestabilizarse, ya que el litigante perdedor puede percibir haber estado lidiando tanto contra su contradictor como contra el juez. Eventualmente, esta percepción podría causar que la parte perdedora se resista a cumplir la sentencia, y asimismo, que disminuya la autoridad del tribunal en el largo plazo. Por ello, buena parte del proceso y el comportamiento judicial se explican como un intento de garantizar la imparcialidad y evitar el quiebre de este mecanismo de resolución de conflictos ${ }^{64}$.

En la jurisdicción constitucional, los incentivos para mantener la lógica de la triada y enfatizar la imparcialidad a nivel discursivo son aún mayores que en un proceso judicial

\footnotetext{
61 Barroso (2010) pp. 145. 165.

62 Zagrebelsky (2007) pp. 101-102. En una tesis similar Dworkin (1985) p. 38.

63 Häberle (1997) pp. 240-243.

${ }^{64}$ Shapiro (1981) pp. 1-16.
} 
ordinario $^{65}$. Los jueces constitucionales muchas veces deben decidir sobre asuntos que dividen profundamente a la comunidad, tratando cuestiones básicas de la organización social como el sistema educativo y el rol del mercado. En otras ocasiones, la jurisdicción constitucional compone la última barrera de defensa de los derechos fundamentales frente a la acción u omisión del estado, como sucede en muchos de los casos de tutela. Y los jueces deben acometer esta última tarea aun cuando, a nivel de la sociedad, son percibidos indistintamente como una pieza integrante del mismo estado.

Sin embargo, los argumentos desarrollados por autores como Barroso, Zagrebelzky o Häberle -citados al inicio de este acápite- no deben conducirnos a asumir que los jueces actuarán siempre desde una posición de imparcialidad. Indudablemente, los magistrados parecerían estar en una posición de mayor neutralidad e independencia que los legisladores y las agencias administrativas. Pero esta es una apreciación relativa, no absoluta.

Los jueces integrados en tribunales colegiados -como resultan ser todas las cortes que resuelven de manera definitiva las controversias constitucionales-, votan en su proceso de deliberación, dirimiendo sus diferencias por la regla de mayoría. En este proceso, su comportamiento podría estar influido por un sinfín de variables extrajurídicas, especialmente en aquellas materias en que las disposiciones a interpretar posean una textura abierta que permita cierta laxitud hermenéutica. Este tipo de situaciones no están ausentes de los debates políticos y académicos sobre la jurisdicción constitucional. No es casual que el proceso de nombramiento de los jueces en los altos tribunales crecientemente atienda a sus distintas sensibilidades en materias morales o socio-económicas. Asimismo, es posible que diversas regulaciones de la organización judicial -como un periodo breve para el ejercicio en el cargo-, hayan sido diseñadas para conducir a los jueces a actuar considerando los eventuales escenarios políticos y económicos futuros. Tales factores han sido estudiados detenidamente, originando algunas corrientes académicas que intentan explicar el comportamiento de los magistrados basándose en aspectos tan disímiles como sus preferencias (attitudinal model) o su respuesta estratégica al contexto político (rational choice) ${ }^{66}$. Por ello es posible afirmar que una teoría de la jurisdicción que ignore las variables antes señaladas no parece ser sino una ficción.

La incidencia de factores extrajurídicos resulta problemática desde la lógica de la triada, descrita más arriba. Cada vez que los jueces deciden dentro de su espacio de discrecionalidad, es posible que sus preferencias influyan en la sentencia. Al resolver sobre asuntos similares, es de esperar que los jueces actúen de forma consistente a lo largo del tiempo, constituyendo una especie de patrón identificable (por ejemplo, pro reo, pro empresa, pro trabajador). Si estas pautas de decisión tienen efecto en los procesos de ascenso y nombramiento de los jueces, o parecen estar coordinadas estratégicamente con la actuación de otros actores políticos, podrían prontamente ser entendidas como una actitud partisana, quebrando la percepción de imparcialidad del tribunal.

\footnotetext{
65 Shapiro (1981) pp. 27-28.

66 Para un resumen de distintos modelos que explican el proceso de toma de decisiones judiciales, ver por ejemplo: Seagal y Spaeth (2002) pp. 44-114.
} 
Para intentar salvar estos cuestionamientos, algunos autores neoconstitucionalistas -como Alfonso García Figueroa-, han afirmado que la motivación es un asunto propio de las ciencias sociales o de un realismo jurídico ajeno a nuestra tradición. Lo relevante para el derecho sería que las decisiones judiciales, con prescindencia de su motivación psicológica o estratégica, estén adecuadamente justificadas en razones constitucionales. Para ello, utilizan ejemplos teóricos que resultan altamente improbables, como que no existen inconvenientes conceptuales para que un juez partidario del Ku-Kux Klan dicte una sentencia justa respecto de un ciudadano de raza negra. Con un correcto razonamiento y las causales de implicancia y recusación bastaría para despejar cualquier objeción a falta de imparcialidad judicial ${ }^{67}$. No obstante, tales observaciones permanecen en lo meramente especulativo, sin lograr despejar los inconvenientes que plantea las posibles sensibilidades ideológicas al interior de los tribunales.

Evidentemente, es deseable que los jueces no sean individuos apáticos con la sociedad en la que viven pues, por la propia naturaleza de su función, requieren un alto nivel de compromiso que les permita enfrentar la resolución de conflictos. En este sentido, resulta natural que puedan desarrollar algún tipo de preferencia moral o política dentro en su esfera personal. Ello no debería acarrear ningún tipo de censura. Lo que resulta problemático para las democracias contemporáneas, es que el nuevo constitucionalismo ha permitido amplios espacios de discreción debido a la mayor indeterminación de los principios establecidos en la carta fundamental. $\mathrm{O}$ en otras palabras, ha abierto oportunidades para que aquellas preferencias abrazadas por los jueces se manifiesten.

\section{LAS FUNCIONES DEL MODELO TEÓRICO: LOS DILEMAS DE LA JUSTIFICACIÓN DE LAS DECISIONES Y DE LA RESPONSABILIDAD POLÍTICA}

Hasta ahora, hemos revisado brevemente distintos atributos de la figura del juez racional. Sin embargo, pese a su sofisticación académica, parece iluso concluir que ellos hubieren sido desarrollados con propósitos meramente intelectuales. Por ello es necesario preguntarse ¿`cuál es la función que cumplen estos atributos que en gran medida resultan ficticios? La respuesta a aquella pregunta pareciera no estar lejos del modelo de legislador descrito por Nino, ideado para suponer una única voluntad tras el derecho y, al mismo tiempo, posibilitar cierto grado de creatividad en su interpretación ${ }^{68}$.

Producto de fenómenos como la aplicación directa de la carta fundamental, los desafíos que los tribunales han empezado a enfrentar difieren de aquellos propios del constitucionalismo liberal clásico. Hoy, es habitual que la judicatura resuelva conflictos en que los litigantes sustentan sus pretensiones en derechos constitucionales contradictorios, o sobre el alcance de principios axiológicos que poseen un importante grado de indeterminación.

\footnotetext{
67 García Figueroa (1999) pp. 59-61.

68 Es conveniente acotar, sin embargo, una importante distinción. Mientras la alegoría de Nino intenta explicar una lógica deductiva propia del método dogmático, el modelo de juez racional enfatiza el carácter reflexivo del magistrado.
} 
La fundamentación teórica de aquellas decisiones no puede ser encontrada directamente en los escritos de Hamilton, ni en las ideas de Kelsen sobre la garantía de corrección formal del proceso legislativo ${ }^{69}$. Por el contrario, los nuevos tipos de decisión judicial parecen contravenir algunos de los presupuestos del primer constitucionalismo, como la separación de poderes.

En este contexto, el modelo de juez racional entregaría un sustento teórico para invitar a confiar en los tribunales, afirmando que, en su nuevo papel, estos no están transgrediendo ni el orden jurídico ni el régimen democrático. En concreto, la función de estas hipótesis consistiría en dar una salida a los dilemas propios de la justificación de un nuevo tipo de decisión judicial creativa y de la responsabilidad política del juzgador.

En primer lugar, el modelo de juez racional intenta veladamente justificar decisiones que en realidad significan un grado importante de discrecionalidad. Ello resulta claro, por ejemplo, respecto de las sentencias en que los jueces dirimen conflictos ponderando principios o derechos fundamentales cuyos alcances resultan antagónicos. Debido a que la constitución incorpora un repertorio genérico de valores, distintos litigantes pueden fundar sus pretensiones en derechos fundamentales contrapuestos. En la práctica, frecuentemente nos encontraremos con conflictos de esta naturaleza, como aquellos que aparecen entre el derecho a la honra y el derecho a la información, o entre la propiedad privada y el derecho a vivir en un ambiente limpio, por nombrar solo algunos. Siendo aquellos derechos igualmente válidos, estos conflictos no pueden ser solucionados mediante un criterio de mera especialidad normativa ${ }^{70}$. Para resolverlos, los jueces han desarrollado la técnica de la ponderación, consistente en establecer una especie de jerarquía axiológica ajustada al caso concreto que deben resolver. Esto quiere decir que el juez determina, para aquella situación en particular, que debe preferirse la aplicación de uno de los derechos o principios en cuestión, asignándoles un peso por razones jurídicas, éticas o políticas. Para algunos autores, como Alexy, esta técnica debería buscar una especie de razonamiento objetivo de optimización que trata de realizar ambos derechos tanto como sea posible ${ }^{71}$. No obstante, desde cualquier perspectiva, la ponderación constituiría una actividad valorativa por parte del juez que significa ejercer cierto margen de discrecionalidad ${ }^{72}$.

Aquella actividad, sin embargo, no resulta cuestionable para los partidarios de esta corriente. Por ejemplo, Alexy rechaza que la ponderación induzca al subjetivismo, pues puede hacerse operativamente mediante un procedimiento racional estructurado, el que en pasos sucesivos consideraría el grado de satisfacción de los derechos involucrados y justificaría el proporcional detrimento de uno de ellos ${ }^{73}$. Luis Prieto Sanchís, en otro argumento en una dirección similar, afirma que la ponderación no amenaza la supremacía del legislador, en la medida que esos derechos son parte del ordenamiento y, por tanto, "parámetros de enjuicia-

\footnotetext{
9 Stone Sweet (2000) pp. 32-38.

70 Prieto Sanchís (2003) p. 142; Dworkin (1977) pp. 26-27.

71 Alexy (2002) p. 47; Alexy (2005) pp. 572-577; Alexy (2010a) pp. 157-161.

2 Prieto Sanchís (2003) p. 151.

3 Alexy (2005) pp. 572-577.
} 
miento directamente aplicables" 74 . No obstante, lo cierto es que en la práctica los magistrados deciden sin un método estricto para el juicio de ponderación, y que no existe un solo criterio para determinar cómo ha de construirse aquella jerarquía axiológica ${ }^{75}$.

Algo similar puede afirmarse respecto de la aplicación judicial de principios jurídicos amplios. Las constituciones contemporáneas han incorporado un ambicioso catálogo de principios y derechos fundamentales redactados de manera indeterminada. Para utilizarlos en su razonamiento, el tribunal debe resolver sobre el alcance de su contenido. Habitualmente, esta actividad no se limita a aclarar la ambigüedad de una norma, sino que constituye una verdadera labor creativa, pues implica establecer consecuencias no expresas directamente en la letra de la constitución ${ }^{76}$.

Tal labor creativa de los jueces se ha convertido en un constante, como en el caso de la Corte Constitucional Italiana. Esta ha desarrollado numerosos criterios no establecidos expresamente -llamados sobreintepretación-, como el derecho a informar y ser informado a partir de la disposición sobre la libertad de emitir opinión ${ }^{77}$. En Latinoamérica, igualmente, los tribunales han empezado a reconocer lo que la doctrina denomina derechos implícitos, es decir, derechos fundamentales no expresos dentro del orden constitucional, originados a partir de la idea de dignidad humana o de normas de derecho internacional ${ }^{78}$.

Evidentemente, las consecuencias de esta labor creadora son importantísimas para la práctica jurídica. Debido a que los derechos y principios constitucionales pueden incidir en todos los ámbitos de la vida social, para algunos autores su aplicación desemboca en la omnipresencia judicial ${ }^{79}$. Desde una posición crítica, Guastini explica que en esta lectura del neoconstitucionalismo "no existen espacios para ninguna discrecionalidad legislativa: no hay una cuestión de legitimidad constitucional de la cual se pueda decir que sea solo una political question [...] ajena al conocimiento del juez de la legitimidad constitucional de las leyes" ${ }^{\prime 0}$. Esta visión extensiva no es unánime dentro de esta corriente, aunque, con matices, se ha impuesto ${ }^{81}$.

El modelo de juez racional cumple una función central en justificar veladamente esta variedad de decisión judicial creativa. La figura del juez Hércules de Dworkin permite afirmar que los tribunales estarían únicamente siendo consistentes con la integridad del ordenamiento jurídico ${ }^{82}$. Del mismo modo, Alexy describe la capacidad de corrección del razonamiento judicial apuntando a que los magistrados toman decisiones bajo criterios objetivos ${ }^{83}$. Al fin y al cabo, los atributos del juez racional ofrecen distintos argumentos para

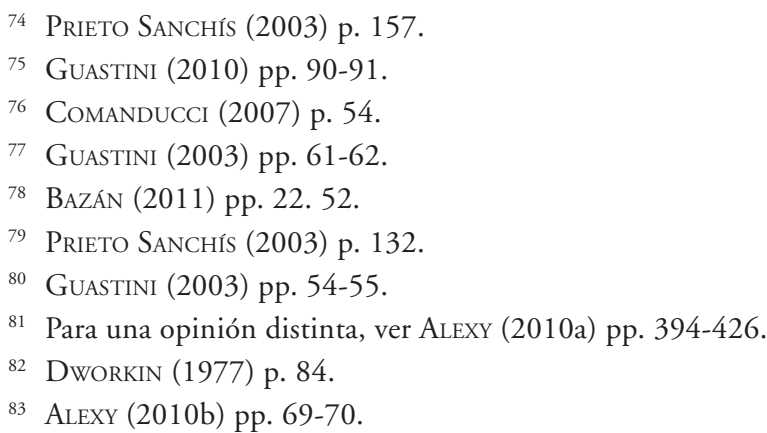


sostener que los magistrados no están creando retroactivamente derecho ni aplicando un capricho arbitrario.

En segundo lugar, el modelo teórico bajo análisis busca proveer una respuesta al dilema de la responsabilidad política del juez. En parte importante de la teoría del neoconstitucionalismo existe una sospecha hacia el proceso político, buscando explicar los motivos por los que la jurisdicción posee un rol correctivo por sobre la ley ${ }^{84}$. Sin embargo, aquella sospecha convive con la afirmación de que los tribunales no reemplazan a los órganos que representan directamente a la soberanía popular. Tal como destaca Carlos Gaviria, ex magistrado de la Corte Constitucional de Colombia, los jueces han debido enfrentar la necesidad de crear derecho, pero ello no implica un intento deliberado de "usurpar las funciones del legislador" 85 . Este dilema puede resumirse en una especie de doble fidelidad, tanto hacia su rol de garante de las garantías constitucionales como hacia el régimen democrático ${ }^{86}$. No es casual que la teoría del neoconstitucionalismo haya girado permanentemente en torno a explicar cómo un órgano cuyos miembros no son electos puede invalidar la legislación ${ }^{87}$.

Para salvar aquel dilema, todos los atributos del juez racional de un modo u otro buscan reconectar al magistrado directamente con la ciudadanía, desde donde emanaría la fuente última de legitimidad del poder público. Según hemos analizado, Alexy plantea que las decisiones constitucionalmente correctas serían aceptadas en el largo plazo por ciudadanos desinteresados, y que los magistrados de la corte detentarían un tipo particular de representación política, distinta de una delegación electoral ${ }^{88}$. Dworkin describe al juez Hércules como un reconstructor de la moralidad pública, contenida tanto en la integridad del sistema jurídico como a nivel de la práctica social ${ }^{89}$. Adicionalmente, diversos jueces -como Luis Roberto Barroso-, han expresamente desarrollado la idea de que el juez canaliza una especie de conciencia mayoritaria de la comunidad ${ }^{90}$.

Aunque de forma menos notoria, este vínculo puede inclusive observarse en la definición que algunos autores realizan de la imparcialidad judicial. Por ejemplo, Luis Prieto Sanchís sostiene que las condiciones que informan el proceso, como la independencia de los jueces y la obligación de motivar las sentencias, constituyen rasgos que les habilitarían para crear derecho de una manera que, indirectamente, resulta aceptable desde la perspectiva democrática. Así las cosas, señala: "si conjugamos esas virtudes formales con las exigencias de legitimidad democrática, incluso resulta posible concebir el propio proceso judicial

\footnotetext{
84 Gaviria díaz (2002) p. XiV; Barroso (2016); Zagrebelsky (2003) p. 38.

85 Gaviria Díaz (2002) pp. XIII-XIV.

86 Zagrebelsky (2003) p. 149.

${ }^{87}$ El modelo de juez racional no salva la objeción democrática al judicial review, excepto para situaciones en que la corte corrija una infracción a un texto absolutamente claro de la constitución. En todos los demás casos, el modelo propone recurrir a elementos ajenos a la voluntad soberana manifestada por los mecanismos propios de democracia representativa, como la corrección argumentativa o la integridad del sistema jurídico. Ver por ejemplo: WALDRON (1999) pp. 291-302.

88 "The only way to reconcile constitutional review with democracy, is to conceive of it, too, as representation of the people”. AleXy (2005) p. 578.

89 DwORKIN (1977).

90 Barroso (2016) pp. 148-150.
} 
como una forma de participación ciudadana en la producción del Derecho" "11. Al final del camino, el dilema de la responsabilidad política del juez se soluciona invariablemente mediante una remisión, ya sea oblicua ya sea directa, a la ciudadanía.

\section{CONCLUSIÓN}

Sin duda, el modelo de juez racional constituye una pieza relevante para comprender el lugar de los tribunales en el neoconstitucionalismo. De una forma análoga a la ficción sobre el legislador descrita por Nino, este intenta compatibilizar dos ideales en tensión. Por una parte, los atributos de este modelo buscan permitir soluciones jurídicas que involucran cierta creatividad y adaptación del derecho, es decir, una actividad propiamente dogmática. Por otra parte, ellos al mismo tiempo permiten afirmar que los tribunales realizan tal labor creativa sin abdicar de su adhesión al sistema democrático, tratando de sostener una especie de vínculo ininterrumpido entre la decisión judicial y la sociedad política.

El hecho de no ser empíricamente verificables, no convierte a los atributos del juez racional en una caricatura cínica. Por el contrario, ellos son el producto de un hábito intelectual de los juristas, quienes honestamente intentan dotar de validez a la práctica que describen. Al hacerlo, no solo buscan justificar teóricamente el funcionamiento del derecho, sino que, con un afán pedagógico, proponen asimismo cómo este debería operar. En efecto, también es posible proponer una segunda lectura de estos atributos: una invitación dirigida a los jueces, estimulándolos para intentar ser racionales, consistentes con la integridad del sistema jurídico, imparciales y atentos a la realidad. Tal segunda lectura, sin embargo, difiere en buena parte del propósito original de estas tesis, destinadas a legitimar subrepticiamente una importante área de discreción judicial.

La existencia de este tipo de ficciones teóricas no es nueva en la historia del derecho. Con distintas características las podemos hallar a través de la figura del buen juez en el ius commune medieval ${ }^{92}$. Ciertamente, también la encontramos en el mismo legislador racional propio de la dogmática positivista, explicado por $\mathrm{Nino}^{93}$. No obstante, es conveniente indicar que la anterior práctica jurídica descansaba en un acervo cultural y ético relativamente compartido, mientras que el actual modelo de juez racional se desenvuelve en un contexto totalmente distinto, en el que la modernidad ha ido diluyendo aquellos lazos comunes que determinan el acuerdo sobre lo que es justo y moralmente aceptable. Por ello, los dilemas de la justificación de la discrecionalidad y de la responsabilidad política hoy resultan más apremiantes.

El modelo de juez racional ha sido un intento de explicar un nuevo tipo de actividad jurisdiccional que la misma sociedad política ha puesto sobre los hombros de los tribunales. La necesidad de supervigilar la constitucionalidad de las leyes, o el requerimiento de aplicar principios jurídicos y derechos cuyo alcance es indeterminado, no es un fenómeno que haya sido incitado por los jueces, quienes muchas veces han aceptado aquellos desafíos con

\footnotetext{
91 Prieto Sanchís (1993) p. 119.

92 TAU (1992) pp. 487-493.

93 Nino (2003). pp. 328-347.
} 
moderación y nobleza. En parte, estos fenómenos han nacido de la creciente fragmentación política y el fracaso de nuestros intentos de reducir la complejidad del derecho.

Pese a lo anterior, resulta inadmisible asumir acríticamente estos atributos, otorgándole el carácter de verdades que ignoran las limitaciones de los magistrados. Tal como sería absurdo creer ciegamente en un legislador omnisciente, preciso y único, resulta insensato atribuir a los atributos del juez racional el carácter de realidades absolutas. Puede haber innumerables motivos para reconocer un nuevo rol de los tribunales y la legitimidad del judicial review -como la propia autolimitación del poder frente a la incertidumbre de los nuevos escenarios políticos-. No obstante, ninguno de ellos pasa por aceptar como verdades que los jueces son una expresión de la razón institucionalizada o seres angélicos capaces de leer inequívocamente los sentimientos morales de la sociedad.

Para el Derecho, una de las interrogantes de la hora presente es cómo limitar aquellos espacios de discrecionalidad que el neoconstitucionalismo ha abierto sin restar efectividad a los principios y derechos establecidos en la carta fundamental. Con este propósito se han escrito interesantes trabajos que insinúan algunas soluciones a este desafío. Entre ellas podemos destacar una definición más precisa de lo que debemos considerar como polítical questions, una mayor referencia a la ley al momento de materializar el alcance de la constitución, una conceptualización de los derechos fundamentales que permita tests de razonamiento más robustos que no se agoten en el mero juicio de ponderación, y el establecimiento de mecanismos que permitan la colaboración institucional entre jueces y legisladores $^{94}$. Del éxito de estos intentos depende superar una aproximación ingenua a la ficción del juez racional. Solo de esa manera podremos evitar se cumpla la inscripción contenida en aquel viejo grabado del pintor español Francisco de Goya, quien nos advierte que, en ocasiones, los sueños de la razón pueden producir sus propios monstruos ${ }^{95}$.

\section{BIBLIOGRAFÍA CITADA}

Acosta, Paola (2014): Diálogo Judicial y Constitucionalismo Multinivel. El Caso Interamericano (Bogotá, Universidad del Externado).

Aldunate, Eduardo (2010): "Aproximación Conceptual y Crítica al Neoconstitucionalismo", Revista de Derecho (Valdivia), Vol. 23: pp. 79-102.

AlEXY, Robert (2005): "Balancing, constitutional review, and representation", International Journal of Constitutional Law, No 3: pp. 572-581.

Alexy, Robert (2007): Teoría de la argumentación jurídica (Madrid, Centro de Estudios Políticos y Constitucionales).

Alexy, Robert (2010a): A Theory of Constitutional Rights (New York, Oxford University Press).

Alexy, Robert (2010b): An Argument against Injustice. A Reply to Legal Positivism (New York, Oxford University Press).

\footnotetext{
${ }^{4}$ Nino (1996) pp. 196-216. Silva (2016); Urbina (2017) pp. 215-252; Tushnet (2014).

95 Goya (1799) p. 43r.
} 
Alexy, Robert (2015): "Legal Certainty and Correctness", Ratio Juris, Vol. 28 No 4: pp. 441-451.

Barroso, Luis Roberto (2007): "El neoconstitucionalismo y la constitucionalización del derecho en Brasil", Revista de Derecho (Universidad de Montevideo), No 12: pp. 25-50.

BARROSO, Luis Roberto (2016) "La Razón sin voto: la función representativa y mayoritaria de las cortes constitucionales", en Gargarella, R. y Niembro, R (eds.), Constitucionalismo Progresista. Un Homenaje a Mark Tushnet (Ciudad de México, UNAM) pp. 137-165.

BaZÁn, Víctor (2011): "La Corte Suprema de Justicia Argentina y la Protección de los derechos fundamentales", en ReY, Fernando (ed.) Los derechos en Latinoamérica: tendencias judiciales recientes (Madrid, Editorial Complutense) pp. 21-57.

Bernal Pulido, Carlos (2007): "Refutación y Defensa del Neoconstitucionalismo", en Carbonell, Miguel (ed.), Teorías del Neoconstitucionalismo (Madrid, Trotta - UNAM.) pp. 289-325.

Capelletti, Mauro (1986): ¿Renegar de Montesquieu? La Expansión y la Legitimidad de la Justicia Constitucional”, Revista Española de Derecho Constitucional. No 17: pp. 9-46.

Carbonell, Miguel (2003): "Nuevos tiempos para el constitucionalismo", en Carbonell, Miguel (ed.) Neoconstitucionalismo(s) (Madrid, Trotta) pp. 9-12.

Carbonell, Miguel (2007): "El neoconstitucionalismo en su laberinto" en Carbonell, Miguel (ed.), Teoría del neoconstitucionalismo (Madrid, Trotta) pp. 9-12.

Comanducci, Paolo (2002): "Formas de (neo)constitucionalismo: Un análisis metateórico." Isonomía, No 16: pp. 89-111.

Comanducci, Paolo (2007): "Modelos de Interpretación de la Constitución" en CARBONELL, Miguel (ed.), Teoría del neoconstitucionalismo (Madrid, Trotta) pp. 41-67.

Correa Sutil, Jorge (1989): "Formación de Jueces para la democracia", Revista de Ciencias Sociales, No 33-34: pp. 271-320.

Cotterrell, Roger (1992): The Politics of Jurisprudence. A Critical Introduction to Legal Philosophy (Philadelphia, University of Pennsylvania Press).

Couso, Javier (2007): "The Seduction of Judicially Triggered Social Transformation. The Impact of the Warren Court in Latin America”, en Scheiber, Harry (ed.), Earl Warren and the Warren Court. The Legacy in American and Foreign Law (Plymouth, Lexington) pp. 237-263.

Dworkin, Ronald (1977): Taking Rights Seriously (Cambridge, Harvard University Press).

Dworkin, Ronald (1985): A Matter of Principle (Cambridge, Harvard University Press).

Dworkin, Ronald (1986): Law's Empire (Cambridge, Harvard University Press).

Dworkin, Ronald (1996): Freedom's Law. The Moral Reading of the American Constitution (Cambridge, Harvard University Press).

Ely, John Hart (1980): Democracy and Distrust. A Theory of Judicial Review (Cambridge, Harvard University Press).

Ferrer Mac-Gregor, Eduardo (2010): "La democracia y el juez constitucional", Revista Iberoamericana de Derecho Procesal Constitucional, No 13: pp. 14-17.

Fioravanti, Maurizio (1996): Los derechos fundamentales. Apuntes para una historia de las constituciones (Madrid, Trotta). 
García Figueroa, Alfonso (1999): "Palabras, palabras, palabras, de lo que el derecho le dice a los jueces", Jueces para la Democracia, No 36. pp. 58-66.

Gaviria Díaz, Carlos (2002): Sentencias. Herejías Constitucionales (Bogotá, Fondo de Cultura Económica).

Goya, Francisco (1799): Los caprichos (Madrid, s/e, Ejemplar en Biblioteca de Catalunya).

Guastini, Ricardo: (2003): "La Constitucionalización del Ordenamiento Jurídico: El caso Italiano”, en Carbonell, Miguel (ed.), Neoconstitucionalismo(s) (Madrid, Trotta) pp. 49-73.

Guastini, Ricardo (2010): Teoría e Ideología de la Interpretación Constitucional (Madrid, Trotta - UNAM).

HäBerle, Peter (1997): "El recurso de amparo en el sistema germano-federal de jurisdicción constitucional”, en García Belaunde, D., Fernández Segado, F. (eds.), La Jurisdicción Constitucional en Iberoamérica (Madrid, Dykinson) pp. 231-285.

Hilbink, Lisa (2012): “The Origins of Positive Judicial Independence”, World Politics, Vol. 64. pp. 587-621.

Hirschl, Ran (2007): Towards Juristocracy. The Origins and Consequences of New-Constitutionalism (Cambridge, Harvard University Press).

Kumm, Mattias (2012): "Alexy's Theory of Constitutional Rights and the Problem of Judicial Review", en KLATt, Matthias (ed.), Institutionalized Reason: The Jurisprudence of Robert Alexy (New York, Oxford University Press) pp. 201-217.

López Medina, Diego (2005): Teoría Impura del Derecho. La trasformación de la cultura jurídica latinoamericana (Bogotá, Legis).

Nino, Carlos Santiago (1996): The Constitution of Deliberative Democracy (New Haven, Yale University Press).

Nino, Carlos Santiago (2003): Introducción al Análisis del Derecho (Buenos Aires, Astrea).

Pitkin, Hanna (1972): The Concept of Representation (Berkeley, The University of California Press).

Pozzolo, Susanna (1998): "Neoconstitucionalismo y especificidad de la interpretación constitucional", Doxa, No 21, Vol. 2: pp. 339-353.

Prieto Sanchís, Luis (1991): "Notas sobre la interpretación constitucional", Revista Centro de Estudios Constitucionales, No 9: pp. 175-198.

Prieto SAnchís, Luis (1993): Ideología e Interpretación Jurídica (Madrid, Tecnos).

Prieto Sanchís, Luis (1998): Ley, Principios, Derechos (Madrid, Dykinson).

Prieto Sanchís, Luis (2003) "Neoconstitucionalismo y Ponderación Judicial”, en CarboNell, Miguel (ed.), Neoconstitucionalismo(s) (Madrid, Trotta) pp. 123-158.

Prieto SAnChís, Luis (2010): "Neoconstitucionalismos (un catálogo de problemas y argumentos)", Anales de la Cátedra Francisco de Suárez, No 44: pp. 461-506.

Prieto Sanchís, Luis (2011): "Luigi Ferrajoli y el neoconstitucionalismo principalista", Doxa, No 34: pp. 229-244.

RaWls, John (2005): Political Liberalism (New York, Columbia University Press).

Rubio LLorente, Francisco (1991): "La Igualdad en la Jurisprudencia del Tribunal Constitucional", Revista Española de Derecho Constitucionalm, No 11: pp. 9-36.

SHAPIro, Martín (1981): Courts. A Comparative and Political Analysis (Chicago, The Chicago University Press). 
Shapiro, Scott J. (2011): Legality (Cambridge, Belknap / Harvard University Press).

Seagal, Jeffrey, Spaeth, Harold (2002): The Supreme Court and the Attitudinal Model Revisited (New York, Cambridge University Press).

SiLva, Luis A. (2016): La dimensión legal de la supremacía constitucional (Santiago, Thomson Reuters)

Stone Sweet, Alec (2000): Governing with Judges. Constitutional Politics in Europe (New York, Oxford University Press).

Tate, C. N., Vallinder, T. (1997): The Global Expansion of the Judicial Power (New York, New York University Press).

TaU, Víctor (1992): Casuismo y Sistema. Indagación histórica sobre el espiritu del derecho indiano (Buenos Aires, Instituto de Investigaciones de Historia del Derecho).

Tushnet, Mark (2014): “Revisión judicial dialógica.” En Gargarella, R (ed.), Por una justicia dialógica. El poder judicial como promotor de la deliberación democrática. (México, Siglo XXI) pp. 105-116.

Urbina, Francisco J. (2017): A critique of proportionality and balancing (Cambridge, Cambridge University Press)

Von Bogdandy, Armin (2015): "Ius Constitutionale Commune en Amércia Latina. Una mirada al constitucionalismo trasformador", Revista de Derecho del Estado. No 34: pp. 3-50.

WaLdRON, Jeremy (1999): Law and Disagreement (New York, Oxford University Press)

Yowell, Paul (2018): Constitutional Rights and Constitutional Design. Moral and Empirical Reasoning in Judicial Review (Oxford, Hart).

Zagrebelsky, Gustavo (2005): El derecho dúctil. Ley, derechos, justicia (Madrid, Trotta).

Zagrebelsky, Gustavo (2007): "Jueces Constitucionales", en Carbonell, Miguel (ed.), Teoría del neoconstitucionalismo (Madrid, Trotta) pp. 91-104. 